\title{
Rosuvastatin reduces the recurrence rate following catheter ablation for atrial fibrillation in patients with heart failure
}

\author{
GUOJUN ZHAO*, LEIMING WU*, YUZHOU LIU, LU GAO, YANG CHEN, RUI YAO and YANZHOU ZHANG* \\ Department of Cardiology, The First Affiliated Hospital of Zhengzhou University, \\ Zhengzhou, Henan 450052, P.R. China
}

Received October 30, 2016; Accepted December 14, 2016

DOI: $10.3892 /$ br.2017.844

\begin{abstract}
The aim of the present study was to assess whether rosuvastatin could reduce the recurrence rate of atrial fibrillation (AF) in patients with heart failure (HF) following catheter ablation (CA). A total of 107 patients with HF and AF who underwent $\mathrm{CA}$ of $\mathrm{AF}$ by endocardial mapping and radiofrequency between June 2012 and May 2014 were recruited. The patients were randomly divided into three subgroups: i) Administered with $10 \mathrm{mg}$ rosuvastatin daily following ablation (group $1, n=36$ ); ii) administered with $20 \mathrm{mg}$ rosuvastatin daily following ablation (group 2, $\mathrm{n}=36$ ); and iii) only treated with conventional treatment of HF following ablation (group 3, $n=35$ ). After the procedure, patients were followed in the outpatient clinic by interrogation of Holter monitoring. The AF recurrence rate of group 2 was low in comparison with group $1(22.2 \%$ vs. $38.9 \%, \mathrm{P}=0.013)$ and group 3 (22.2\% vs. $48.6 \%, \mathrm{P}=0.021)$. In comparison with baseline, the parameters of the left ventricular ejection fraction, left atrial diameter (LAD), and the levels of N-terminal pronatriuretic peptide and hypersensitive $\mathrm{C}$-reactive protein (hs-CRP) were all improved in three groups. Furthermore, multivariate analysis demonstrated that LAD [hazard ratio (HR): 1.12, 95\% confidence interval (CI): 1.06-1.67, $\mathrm{P}=0.049]$, hs-CRP (HR: 1.37, 95\% CI: 1.11-1.92, $\mathrm{P}=0.002)$ and duration of AF (HR: 1.14, 95\% CI: 1.09-1.18, P=0.011) were independent predictors of AF recurrence in patients with $\mathrm{HF}$ following CA. Therefore, the present study has demonstrated that treatment with $20 \mathrm{mg}$ rosuvastatin daily following CA was able to significantly decrease the recurrence rate of AF in patients with $\mathrm{HF}$, and LAD, hs-CRP, and duration of AF were independent
\end{abstract}

Correspondence to: Dr Yanzhou Zhang, Department of Cardiology, The First Affiliated Hospital of Zhengzhou University, Jian-She-Dong Road, Zhengzhou, Henan 450052, P.R. China

E-mail: zhangyanzhou016@sina.com

*Contributed equally

Key words: rosuvastatin, atrial fibrillation, heart failure, catheter ablation, recurrence predictors of AF recurrence in patients with $\mathrm{HF}$ following $\mathrm{CA}$. In conclusion, the present study has also demonstrated that $\mathrm{CA}$ may improve cardiac function in patients with $\mathrm{HF}$ and $\mathrm{AF}$.

\section{Introduction}

Heart failure (HF) and atrial fibrillation (AF) occurring concomitantly is one of the most common cardiac conditions encountered in the clinic, and the incidence of HF complicated by AF has been increasing $(1,2)$. During the pathophysiological process, HF and AF influence and promote each other, forming a vicious circle (3). Due to the side-effects and low efficiency of anti-arrhythmic drugs, an increasing number of clinicians are developing a keen interest in non-drug therapy for $\mathrm{HF}$ and AF (4). In recent years, catheter ablation (CA) has provided a novel direction for the treatment of HF complicated with AF, based on its advantages in the restoration of sinus rhythm, improvement of cardiac function and long-term prognosis (5). However, one previous meta-analysis study demonstrated that the ablation success rate of HF patients with AF is only $\sim 60 \%$ (6). Therefore, how to reduce the recurrence rate of $\mathrm{AF}$ with $\mathrm{HF}$ has become a hot research topic. It has been demonstrated that statins may prevent the occurrence of AF by virtue of their being antioxidants and anti-inflammatory agents, and through the stabilization of cardiomyocyte membranes $(7,8)$. These characteristics of statins are closely linked with the pathological processes of HF and AF. The GISSI-HF trial, which explored the effects of rosuvastatin in patients with chronic heart failure, demonstrated that rosuvastatin is able to reduce the occurrence of AF in patients with HF (9). Furthermore, Xia et al (10) demonstrated that rosuvastatin decreases the early recurrence of AF following electrical cardioversion with reduced asymmetric dimethylarginine levels. However, the effects of rosuvastatin on the recurrence rate of $\mathrm{AF}$ in patients with $\mathrm{HF}$ have yet to be fully elucidated. Therefore, the present study aimed to ascertain whether rosuvastatin was able to reduce the recurrence rate following $\mathrm{CA}$ for $\mathrm{AF}$ in patients with $\mathrm{HF}$.

\section{Materials and methods}

Patient population. All patients diagnosed with $\mathrm{HF}$ and AF who underwent CA of AF between June 2012 and May 2014 were recruited in the present study. Both the definition and 
classification of AF and HF were based on the guidelines of 2014's American College of Cardiology (ACC)/American Heart Association Task Force on Practice Guidelines (AHA)/Heart Rhythm Society (HRS) (5), 2013's American College of Cardiology Foundation (ACCF)/AHA/HF guidelines (11) and the functional classification of the New York Heart Association (NYHA) (12). Patients who were suffering from moderate-to-severe valvular disease, inflammatory diseases, coronary artery disease, a previous incidence of AF/CA, surgery, trauma, hyperthyroidism or hypothyroidism, anomalous pulmonary venous connection, revealed left atrium thrombus or anticoagulation contraindications were excluded. Eligible patients were randomly assigned in proportions of 1:1:1 to receive an additional $10 \mathrm{mg}$ rosuvastatin daily (group 1), an additional $20 \mathrm{mg}$ rosuvastatin daily (group 2), or only a conventional treatment of HF following ablation [group 3, the control group: Specifically, patients with heart failure were treated with an appropriate pharmacological therapy, such as angiotensin-converting enzyme inhibitors/angiotensin receptor blockers (ACEI/ARBs), $\beta$-blocker, digoxin or diuretics, except in the case of treatment with rosuvastatin, when necessary, according to the 2016 ESC Guidelines for the Diagnosis and Treatment of Acute and Chronic Heart Failure (13)]. Rosuvastatin (Crestor ${ }^{\circledR} ; 10 \mathrm{mg}, 7$ pills per packet) was obtained from AstraZeneca (Cambridge, UK).

The present study was approved by the Ethics Committee of the First Affiliated Hospital of Zhengzhou University Institute (Zhengzhou, China), and informed consent was obtained from the patients prior to their participation in this study.

Procedure of radiofrequency $C A$. All the subjects received warfarin therapy for $\geq 1$ month prior to the surgery, maintaining the international normalized ratio between 2.0-3.0. Warfarin was discontinued 3 days prior to the surgery, and bridging with low-molecular-weight heparin (Chia Tai Haier Pharmaceutical Co., Ltd., Qingdao, China) was performed. Within $24 \mathrm{~h}$ prior to the surgery, transesophageal echocardiography was performed, or a pulmonary vein computed tomography angiography examination was conducted, to exclude left atrial thrombus. In addition, anti-arrhythmic drug therapy was stopped $\geq 1$ week prior to the ablation, with the exception of amiodarone, which was orally administered $(0.2 \mathrm{mg})$ three times a day 7 days prior to the ablation. Following local anesthesia, the right and left femoral vein were punctured using Seldinger's technique (two 8F sheets were placed on the right femoral vein, and one $6 \mathrm{~F}$ sheet was placed on the left femoral vein). Subsequently, a 10-pole mapping electrode (Lasso ${ }^{\circledR}$; Biosense Webster, Inc., Diamond Bar, CA, USA) was inserted into the coronary sinus through the $6 \mathrm{~F}$ sheath. Next, a Swartz ${ }^{\mathrm{TM}}$ sheath (St. Jude Medical, Inc., St. Paul, MN, USA) was used for the transseptal puncture. After the transseptal puncture, heparin was administered at a concentration of $100 \mathrm{U} / \mathrm{kg}$ to the patients, and the Swartz ${ }^{\mathrm{TM}}$ sheath was continuously rinsed with heparin saline. After directing the Swartz ${ }^{\mathrm{TM}}$ sheath to the pulmonary vein ostium along the guide-wire, both sides of the pulmonary vein angiography were subsequently performed to determine the anatomical location of the pulmonary vein openings. Ten pole-circular mapping electrodes (Lasso ${ }^{\circledR}$; Biosense Webster, Inc.) were subsequently directed to each pulmonary vein ostium through the Swartz ${ }^{\mathrm{TM}}$ sheath, recording the pulmonary
Table I. Patient characteristics.

\begin{tabular}{|c|c|}
\hline Characteristic & Value \\
\hline Age, years & $63.3 \pm 13.6$ \\
\hline Female, n (\%) & $58(54.2)$ \\
\hline Smoking, n (\%) & $17(15.9)$ \\
\hline Hypertension, n (\%) & $21(19.6)$ \\
\hline Diabetes mellitus, n (\%) & $17(15.9)$ \\
\hline \multicolumn{2}{|l|}{ Type of AF, n (\%) } \\
\hline Paroxysmal & $24(22.4)$ \\
\hline Persistent & $45(42.1)$ \\
\hline Permament & $38(35.5)$ \\
\hline Duration of AF, months & $37.8(4.0-70.3)$ \\
\hline \multicolumn{2}{|l|}{ Comorbidities } \\
\hline \multicolumn{2}{|l|}{ Laboratory data } \\
\hline hs-CRP, mg/l & $2.00 \pm 1.21$ \\
\hline $\mathrm{eGFR}, \mathrm{ml} / \mathrm{min} / 1.73 \mathrm{~m}^{2}$ & $63.3 \pm 18.2$ \\
\hline NT-proBNP level, pg/dl & $399.9(65.3-887.5)$ \\
\hline \multicolumn{2}{|l|}{ Echocardiographic parameters } \\
\hline $\mathrm{LAD}, \mathrm{mm}$ & $47.5 \pm 7.9$ \\
\hline LVEDD, mm & $55.6 \pm 10.1$ \\
\hline LVEF, \% & $45.2 \pm 14.1$ \\
\hline NYHA functional class & $2.3 \pm 0.6$ \\
\hline \multicolumn{2}{|l|}{ Medical therapy, n (\%) } \\
\hline ACEI or ARB & $53(49.5)$ \\
\hline Diuretic & $60(56.1)$ \\
\hline$\beta$-blockers & $61(57.0)$ \\
\hline Digoxin & $22(20.6)$ \\
\hline Calcium-channel blockers & $13(12.1)$ \\
\hline \multicolumn{2}{|l|}{ Ablation procedure, n (\%) } \\
\hline PVI & $107(100.0)$ \\
\hline PVI with additional procedure & $88(82.2)$ \\
\hline \multicolumn{2}{|l|}{ Antiarrhythmic drug use, n (\%) } \\
\hline Class 1 & $16(14.9)$ \\
\hline Class 3 & $34(31.8)$ \\
\hline
\end{tabular}

$\mathrm{AF}$, atrial fibrillation; NT-proBNP, N-terminal-pro brain type natriuretic peptide; eGFR, estimated glomerular filtration rate; hs-CRP, high-sensitivity C-reative protein; LAD, left atrial diameter; LVEDD, left ventricular end-diastolic diameter; LVEF, left ventricular ejection fraction; NYHA, New York Heart Association; ACEI, angiotensin-converting enzyme inhibitor; $\mathrm{ARB}$, angiotensin-receptor blocker; PVI, pulmonary vein isolation.

vein potential in order to guide pulmonary vein ablation. A $3.5 \mathrm{~mm}$ saline irrigated ablation catheter (Thermo-cool Navistar; Biosense Webster, Inc.) was subsequently delivered to the left atrium through the Swartz ${ }^{\mathrm{TM}}$ sheath. The left atrium and pulmonary veins were reconstructed according to their three-dimensional structure following the guidance system of CARTO $^{\circledR}$ (Biosense Webster, Inc.). Guided by the CARTO ${ }^{\circledR}$ system, the $3.5 \mathrm{~mm}$ saline infusion thermostat catheter was used to perform the annular ablation along the orifices of 
Table II. Comparison of baseline characteristics of different groups.

\begin{tabular}{|c|c|c|c|c|}
\hline Parameter & $\begin{array}{l}\text { Group } 1 \\
(n=36)\end{array}$ & $\begin{array}{c}\text { Group } 2 \\
(n=36)\end{array}$ & $\begin{array}{c}\text { Group } 3 \\
(\mathrm{n}=35)\end{array}$ & P-value \\
\hline Age, years & $62.2 \pm 11.7$ & $63.1 \pm 14.2$ & $62.7 \pm 13.0$ & 0.31 \\
\hline Female, n (\%) & $22(61.1)$ & $20(55.6)$ & $16(45.7)$ & 0.73 \\
\hline Smoking, n (\%) & $6(16.7)$ & $7(19.4)$ & $4(11.4)$ & 0.19 \\
\hline Hypertension, n (\%) & $7(19.4)$ & $6(16.7)$ & $4(11.4)$ & 0.91 \\
\hline Diabetes mellitus, n (\%) & $8(22.2)$ & $9(30.0)$ & $12(18.2)$ & 0.49 \\
\hline \multicolumn{5}{|l|}{ Type of AF } \\
\hline Paroxysmal, n (\%) & $6(16.7)$ & $7(19.4)$ & $11(31.4)$ & 0.11 \\
\hline Persistent, n (\%) & $17(47.2)$ & $15(41.7)$ & $13(37.1)$ & 0.94 \\
\hline Permanent, n (\%) & $13(36.1)$ & $14(38.9)$ & $11(31.4)$ & 0.76 \\
\hline Duration of AF, months & $37.3(3.3-79.9)$ & $34.2(2.3-66.5)$ & $49.0(4.2-83.5)$ & 0.45 \\
\hline \multicolumn{5}{|l|}{ Laboratory data } \\
\hline hs-CRP, mg/l & $2.17 \pm 0.82$ & $1.84 \pm 1.06$ & $2.03 \pm 1.34$ & 0.69 \\
\hline eGFR, $\mathrm{ml} / \mathrm{min} / 1.73 \mathrm{~m}^{2}$ & $62.1 \pm 17.0$ & $67.5 \pm 20.3$ & $61.2 \pm 18.7$ & 0.21 \\
\hline NT-proBNP level, pg/dl & $365.9 \pm 136.8$ & $421.7 \pm 182.1$ & $359.5 \pm 129.3$ & 0.41 \\
\hline \multicolumn{5}{|l|}{ Echocardiographic parameters } \\
\hline $\mathrm{LAD}, \mathrm{mm}$ & $46.7 \pm 9.1$ & $47.3 \pm 7.2$ & $47.9 \pm 9.2$ & 0.72 \\
\hline LVEDD, mm & $56.9 \pm 9.6$ & $53.7 \pm 11.0$ & $54.1 \pm 9.3$ & 0.66 \\
\hline LVEF, \% & $46.3 \pm 14.6$ & $45.2 \pm 13.5$ & $49.5 \pm 15.7$ & 0.76 \\
\hline NYHA functional class & $2.5 \pm 0.8$ & $2.3 \pm 0.5$ & $2.2 \pm 0.7$ & 0.89 \\
\hline \multicolumn{5}{|l|}{ Medical therapy } \\
\hline ACEI or ARB, $(\mathrm{n}, \%)$ & $18(50.0)$ & $21(58.3)$ & $15(42.9)$ & 0.29 \\
\hline Diuretic & $26(72.2)$ & $16(44.4)$ & $18(51.4)$ & 0.93 \\
\hline$\beta$-blockers & $17(47.2)$ & $24(66.7)$ & $20(57.1)$ & 0.62 \\
\hline Digoxin & $6(16.7)$ & $8(22.2)$ & $8(22.9)$ & 0.11 \\
\hline Calcium-channel blockers & $3(8.3)$ & $6(16.7)$ & $4(11.4)$ & 0.59 \\
\hline \multicolumn{5}{|l|}{ Ablation procedure $(\mathrm{n}, \%)$} \\
\hline PVI & $36(100.0)$ & $36(100.0)$ & $35(100.0)$ & NA \\
\hline PVI with additional procedure & $28(77.8)$ & $31(86.1)$ & $29(82.9)$ & 0.88 \\
\hline \multicolumn{5}{|l|}{ Antiarrhythmic drug use, n (\%) } \\
\hline Class 1 & $3(8.3)$ & 4 (11.1) & $7(20.0)$ & 0.57 \\
\hline Class 3 & $12(33.3)$ & $15(41.7)$ & $7(20.0)$ & 0.09 \\
\hline
\end{tabular}

AF, atrial fibrillation; NT-proBNP, N-terminal-pro brain type natriuretic peptide; eGFR, estimated glomerular filtration rate; hs-CRP, high-sensitivity C-reative protein; LAD, left atrial diameter; LVEDD, left ventricular end-diastolic diameter; LVEF, left ventricular ejection fraction; NYHA, New York Heart Association; ACEI, angiotensin-converting enzyme inhibitor; ARB, angiotensin-receptor blocker; PVI, pulmonary vein isolation; NA, not applicable.

the right and left pulmonary veins. The following discharge parameters were set: $34-40 \mathrm{~W}$; flow rate of $17-25 \mathrm{ml} / \mathrm{min}$ ( $2 \mathrm{ml} / \mathrm{min}$ when ablation was not being performed); maximum temperature, $43^{\circ} \mathrm{C}$; discharge time for each point of 20-30 sec. The end-point was determined by the pulmonary vein and the atrium achieving two-way electrical isolation. The majority of patients with paroxysmal and early persistent AF required pulmonary vein isolation alone, although a large number of the patients with prolonged and permanent $\mathrm{AF}$ were required to have an additional complex fractionated electrogram ablation, or a cavotricuspid isthmus or linear ablation. After the ablation, if atrial fibrillation was not restored to normal sinus rhythm, or a switch was made to atrial tachycardia or atrial flutter, then electrical cardioversion was performed.

Follow-up. The detailed medical history of the patient was obtained, and an echocardiography examination, $24 \mathrm{~h}$ Holter monitoring and a series of basic laboratory analyses (see below) were performed prior to the procedure. The follow-up period of the study was 18 months. Patients were followed at 1, 3, 6, 12 and 18 months through the outpatient clinic following the surgery. At the time-point of each follow-up visit, patients received $24 \mathrm{~h}$ Holter monitoring, and were also asked about any symptoms associated with the presence of 
arrhythmia. If the patients were suspected of having had an emerging arrhythmia, but no evidence of this was available at the time of examination, additional $24 \mathrm{~h}$ Holter monitoring and short-duration follow-up were performed. If palpitations arose or the patients experienced any symptoms of arrhythmia during the follow-up, $24 \mathrm{~h}$ Holter monitoring was instantly administered. At the time of 6 and 12 months following CA, an echocardiography was performed, and the laboratory analyses, including assessing the levels of hypersensitive $\mathrm{C}$-reactive protein (hs-CRP) and N-terminal pronatriuretic peptide (NT-proBNP) and estimating the glomerular filtration rate (eGFR), were performed for all the participants. All patients received warfarin for 3 months postoperatively, if there was no recurrence of AF and the CHADS2 score (5) was $\geq 2$. The electrocardiogram was assessed to confirm whether there had been recurrence of any AF or atrial tachycardia for $\geq 30 \mathrm{sec}$. AF occurring within 3 months was not considered to be a recurrence (since this fell within the 'blanking period', during which time recurrences were often managed medically). The primary end-point of this trial was the recurrence of any AF or atrial tachycardia of $>30 \mathrm{sec}$ duration. In addition, the major adverse events were defined as mortality, muscle-associated symptoms, HF hospitalization, or stroke.

Laboratory assessment and echocardiography. The blood samples were collected from the elbow while the patients were supine following a rest period. Plasma hs-CRP levels were analyzed using an automated hs-CRP method (IMMULITE ${ }^{\circledR}$; Diagnostic Products Corp., Los Angeles, CA, USA). The plasma NT-proBNP level was analyzed by electrochemiluminescence in an E170 immunoassay analyzer (Hoffmann-LaRoche, Basel, Switzerland). The eGFR values were calculated using the Modification of Dietin RenalDisease(MDRD) equation modified by the Japanese coefficient (0.881), as described previously (14): [GFR $\left(\mathrm{ml} / \mathrm{min}\right.$ per $\left.1.73 \mathrm{~m}^{2}\right)=0.881 \times 186 \mathrm{x} \mathrm{age}^{-0.203} \times \mathrm{Scr}^{-1.154}$ (if female, $x$ 0.742). The equation provides an accurate eGFR value within the range of GFR $\left.<60 \mathrm{ml} / \mathrm{min} / 1.73 \mathrm{~m}^{2}\right]$. For the echocardiography parameters, the left ventricular ejection fraction (LVEF) was calculated using Simpson's method, whereas the left atrial diameter (LAD) and left ventricular end-diastolic diameter (LVEDD) diameter were assessed using M-mode methods.

Statistical analysis. The measured data were expressed as the mean \pm standard deviation. Baseline characteristics of different groups were compared using the Student's t-test. Enumeration data were represented as $\mathrm{n}$, and as a percentage. Comparisons of categorical variables were made using the Chi-square test or Fisher's exact test. Kaplan-Meier survival curves were used to estimate AF-free survival, and the differences between the curves were compared using the log-rank test. Univariate and multivariate Cox proportional hazard regression analyses were performed to identify the independent predictors of AF recurrence. Data were analyzed using SPSS statistical software, version 17.0 (SPSS, Inc., Chicago, IL, USA). P<0.05 was considered to indicate a statistically significant difference.

\section{Results}

Study population. A total of 107 patients with the complications of $\mathrm{HF}$ and AF were recruited in the present study. Baseline
Table III. Major adverse events during the follow-up.

Major adverse event Group 1 Group 2 Group 3 P-value

\begin{tabular}{lllll}
\hline Stroke & 0 & 0 & 0 & - \\
All cause death & 0 & 0 & 0 & - \\
$\begin{array}{l}\text { Muscle-related } \\
\text { symptoms }\end{array}$ & 0 & 0 & 0 & - \\
HF hospitalization & 2 & 1 & 1 & 0.767 \\
\hline
\end{tabular}

$\mathrm{HF}$, heart failure.

characteristics of the patients are listed in Table I. No statistically significant differences were identified with respect to age, gender, duration of AF, LVEDD, LVEF, type of AF, NYHA functional class, complications, or other aspects among the different groups (Table II). The major adverse events occurred in 4 patients (all were HF hospitalizations) among the participants, and there were no significant differences regarding major adverse events among the 3 groups $(\mathrm{P}=0.767)$ (Table III). No patients were lost during the follow-up.

Ablation outcomes. Successful ablation was accomplished in all patients. Pulmonary vein isolation was successfully accomplished in all patients (100\%). Additional complex fractionated electrogram ablation, cavotricuspid isthmus or linear ablation were performed on a total of 88 patients. No severe complications occurred in any patients. All the patients were restored to a sinus rhythm prior to leaving hospital. Two patients had pericardial effusion, one patient had left groin hematoma due to an inadvertent puncture, but following treatment, all the patients were effectively healed and discharged.

Follow-up results. Up to the end of the follow-up, 68 patients $(63.6 \%)$ were free from AF. In group 1, 14 persons $(38.9 \%)$ suffered recurrence of AF; in group 2, the recurrence rate was $22.2 \%$, while there were 17 individuals (48.6\%) who suffered from recurrence in group 3 . The results demonstrated that treatment with $10 \mathrm{mg}$ rosuvastatin daily following ablation did not reduce the recurrence rate of $\mathrm{AF}$ in patients with $\mathrm{HF}$ in comparison with the control group (38.9 vs. $48.6 \%$; $\mathrm{P}=0.879$ ), whereas treatment with $20 \mathrm{mg}$ rosuvastatin daily following CA was able to significantly decrease the recurrence rate of $\mathrm{AF}$ compared with group 1 (22.2 vs. $38.9 \%, \mathrm{P}=0.013)$ and group 3 ( $22.2 \%$ vs. $48.6 \%, \mathrm{P}=0.021$ ). The Kaplan-Meier curves (Fig. 1) demonstrated that treatment with $20 \mathrm{mg}$ rosuvastatin daily following CA (group 2) could significantly decrease the recurrence rate of $\mathrm{AF}$ compared with group land group $3(\mathrm{P}<0.05$, by log-rank test).

There were no differences in the baseline parameters of LVEF, NYHA functional class, LAD, NT-proBNP, LVEDD and hs-CRP levels in groups 1, 2 and 3. However, in comparison with baseline parameters, LVEF, LAD, NT-proBNP and hs-CRP levels all exhibited improvements in the 3 groups. Regrettably, an inspection of the parameters mentioned above did not reveal any statistically significant differences among groups 1,2 and 3, with the exception of the levels of hs-CRP and LAD during the follow-up (Table IV). 
Table IV. Baseline and follow-up changes in LAD, LVEF, hs-CRP and NT-proBNP.

\begin{tabular}{|c|c|c|c|c|}
\hline Group & Parameter & Baseline & $\begin{array}{l}6 \text { months } \\
\text { after ablation }\end{array}$ & $\begin{array}{l}12 \text { months } \\
\text { after ablation }\end{array}$ \\
\hline \multirow[t]{4}{*}{1} & $\mathrm{LAD}, \mathrm{mm}$ & $46.7 \pm 9.1$ & $45.1 \pm 6.2$ & $43.3 \pm 4.3^{\mathrm{a}, \mathrm{c}}$ \\
\hline & LVEF, \% & $46.3 \pm 14.6$ & $49.5 \pm 14.3$ & $51.4 \pm 12.3^{\mathrm{c}}$ \\
\hline & hs-CRP, mg/l & $2.17 \pm 0.82$ & $0.96 \pm 0.61^{\mathrm{a}}$ & $0.47 \pm 0.26^{\mathrm{a}-\mathrm{d}}$ \\
\hline & NT-proBNP, pg/dl & $365.9 \pm 136.8$ & $282 \pm 97.3^{c}$ & $193 \pm 65.9^{\mathrm{c}, \mathrm{d}}$ \\
\hline \multirow[t]{4}{*}{2} & $\mathrm{LAD}, \mathrm{mm}$ & $47.3 \pm 7.2$ & $43.2 \pm 6.2$ & $39.5 \pm 5.8^{\mathrm{c,d}}$ \\
\hline & LVEF, \% & $45.2 \pm 13.5$ & $48.5 \pm 10.4^{c}$ & $50.1 \pm 9.8^{c}$ \\
\hline & hs-CRP, mg/l & $1.84 \pm 1.06$ & $0.35 \pm 0.47^{\mathrm{b}, \mathrm{c}}$ & $0.23 \pm 0.19^{c, b}$ \\
\hline & NT-proBNP, pg/dl & $421.7 \pm 182.1$ & $312 \pm 107.1^{\mathrm{c}}$ & $213 \pm 87.4^{\mathrm{c}, \mathrm{d}}$ \\
\hline \multirow[t]{4}{*}{3} & $\mathrm{LAD}, \mathrm{mm}$ & $47.9 \pm 9.2$ & $44.9 \pm 5.7$ & $44.3 \pm 5.6^{\mathrm{a}, \mathrm{c}}$ \\
\hline & LVEF, \% & $49.5 \pm 15.7$ & $51.2 \pm 13.5$ & $52.7 \pm 14.2^{\mathrm{c}}$ \\
\hline & hs-CRP, mg/l & $2.03 \pm 1.34$ & $1.11 \pm 0.57^{\mathrm{a}}$ & $0.79 \pm 0.54^{\mathrm{a}, \mathrm{c}}$ \\
\hline & NT-proBNP, pg/dl & $359.5 \pm 129.3$ & $248 \pm 79.4^{\mathrm{c}}$ & $181 \pm 64.3^{c}$ \\
\hline
\end{tabular}

${ }^{a} \mathrm{P}<0.05$ compared with group $2,{ }^{b} \mathrm{P}<0.05$ compared with control group (group 3 ), ${ }^{\mathrm{c}} \mathrm{P}<0.05$ compared with baseline, ${ }^{\mathrm{d}} \mathrm{P}<0.05$ compared with 3 months after ablation. NT-proBNP, N-terminal-pro brain type natriuretic peptide; eGFR, estimated glomerular filtration rate; hs-CRP, high-sensitivity C-reative protein; LAD, left atrial diameter; LVEDD, left ventricular end-diastolic diameter; LVEF, left ventricular ejection fraction; NYHA, New York Heart Association; ACEI, angiotensin-converting enzyme inhibitor; ARB, angiotensin-receptor blocker; PVI, pulmonary vein isolation.

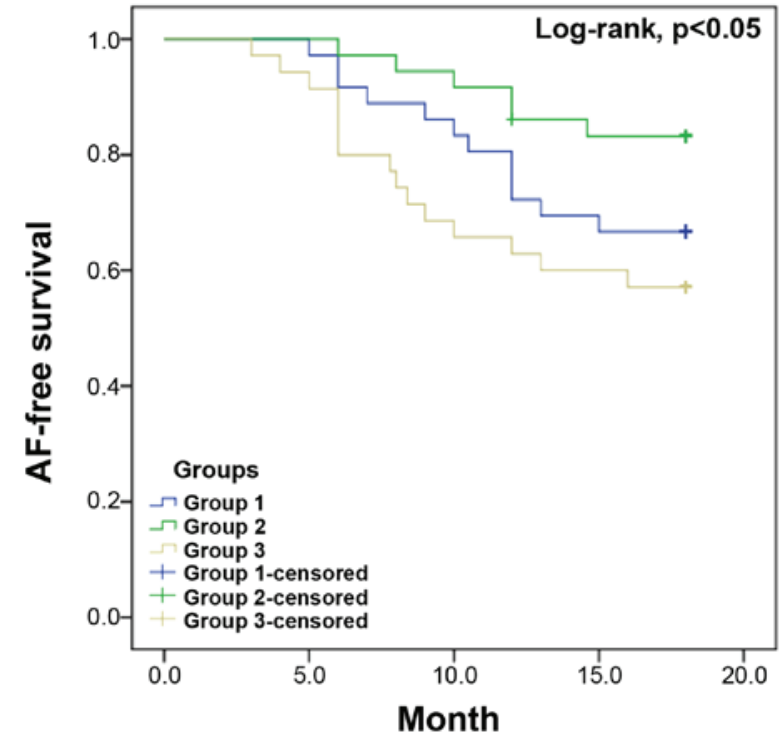

Figure 1. Kaplan-Meier curves for the recurrence of AF. AF, atrial fibrillation.

Univariate analysis (Table V) revealed that the female gender, hs-CRP, non-paroxysmal AF, duration of AF, LVEF and LAD were associated with higher recurrence rates. When multivariate analysis was used to adjust for relevant confounders, only hs-CRP, duration of AF and LAD were associated with higher rates of recurrence (Table VI).

\section{Discussion}

The present study evaluates the effects of a high dose of rosuvastatin in preventing $\mathrm{AF}$ recurrence following $\mathrm{CA}$ in patients with HF. At the same time, the data illustrate that CA may significantly improve cardiac function in patients with $\mathrm{HF}$ and AF, which corroborates the conclusions of previously published studies (15-17). Furthermore, the present study has revealed that hs-CRP, duration of AF and LAD are independent predictors of higher recurrence rates of $\mathrm{AF}$ in patients with HF.

It is well known that statins act as anti-inflammatory and anti-oxidative stress agents, except in the case of regulating lipid metabolism $(18,19)$. In recent times, the role of statins in the treatment of AF has been attracting more attention. Atrium NADPH oxidase 2 (NOX2) serves an important role in the pathophysiological process of AF: The stronger the atrium NOX2 activity, the higher the incidence of AF $(20,21)$. Recalde et al (22) demonstrated that increased AF susceptibility in mice with myocardial-specific NOX2 overexpression was prevented by short-term statin treatment. It may be inferred that the cause could possibly be due to high doses of rosuvastatin inhibiting the activity of NOX2. The role of inflammation in AF is well established. The randomized, placebo-controlled JUPITER trial confirmed that increased levels of hs-CRP were associated with an increased incidence of AF (23). Similarly to the present study, the GISSI-HF trial also demonstrated that administering $10 \mathrm{mg}$ rosuvastatin daily could significantly improve the incidence of new-onset AF in HF patients, although chronic AF patients exhibited no benefits resulting from rosuvastatin therapy (9). Another possible reason for rosuvastatin decreasing the recurrence rate of $\mathrm{AF}$ could be via its powerful functions as an anti-inflammatory and anti-oxidative stress agent. Explanations for why small doses of rosuvastatin were not able to attenuate the recurrence rate may be due to the strength of the anti-inflammatory, anti-oxidative stress, and also that the ability to inhibit the activity of NOX2 is weak. It was observed in the present 
Table V. Univariate analysis comparing patients with and without $\mathrm{AF}$ recurrence.

\begin{tabular}{lcc}
\hline Variable & HR $(95 \% \mathrm{CI})$ & P-value \\
\hline Age, years & $1.02(0.99-1.04)$ & 0.723 \\
Female & $2.84(1.81-4.04)$ & 0.005 \\
Smoking & $0.85(0.20-3.03)$ & 0.973 \\
Non-PAF & $0.74(0.34-0.98)$ & 0.025 \\
Duration of AF, months & $1.03(1.01-1.05)$ & 0.001 \\
Hypertension & $1.07(0.46-2.43)$ & 0.998 \\
Diabetes mellitus & $2.01(0.57-8.34)$ & 0.254 \\
hs-CRP, mg/l & $1.42(1.03-1.89)$ & 0.003 \\
eGFR, ml/min/1.73m² & $0.48(0.16-1.35)$ & 0.101 \\
NT-proBNP level, pg/dl & $1.03(0.72-3.01)$ & 0.104 \\
LAD, mm & $1.08(1.01-1.32)$ & 0.011 \\
LVEDD, mm & $1.00(0.97-1.31)$ & 0.713 \\
LVEF, \% & $1.13(1.06-1.40)$ & 0.035 \\
ACEI or ARB use & $1.56(0.87-2.88)$ & 0.728 \\
Diuretic use & $1.29(0.43-1.97)$ & 0.281 \\
$\beta$-blocker use & $1.26(0.84-1.90)$ & 0.728 \\
Digoxin use & $0.87(0.56-1.43)$ & 0.590 \\
Calcium-channel & $1.70(1.30-2.62)$ & 0.727 \\
blocker use & & \\
Antiarrhythmic drug use & & \\
Class 1 & $1.03(0.69-1.52)$ & 0.444 \\
Class 3 & $1.37(1.02-2.29)$ & 0.997 \\
\hline
\end{tabular}

HR, hazard ratio; CI, confidence interval; NT-proBNP, N-terminal-pro brain type natriuretic peptide; eGFR, estimated glomerular filtration rate; hs-CRP, high-sensitivity C-reative protein; PAF, paroxysmal atrial fibrillation; LAD, left atrial diameter; LVEDD, left ventricular end-diastolic diameter; LVEF, left ventricular ejection fraction; NYHA, New York Heart Association; ACEI, angiotensin-converting enzyme inhibitor; ARB, angiotensin-receptor blocker; PVI, pulmonary vein isolation.

study that $20 \mathrm{mg}$ rosuvastatin administered daily may prevent the recurrence of $\mathrm{AF}$ in patients with $\mathrm{HF}$, although further research is required to elucidate the precise mechanism.

With the rapid development of intervention therapy, the standing of $\mathrm{CA}$ in the treatment of $\mathrm{AF}$ has been steadily improving. The latest RAAFT-2 (24) and MANTRA-PAF trials (25) have demonstrated that, as the first-line treatment, CA for paroxysmal AF had improved long-term effects compared with anti-arrhythmic drug therapy. In addition, Rillig et al (26) demonstrated that, for patients with a reduced ejection fraction, CA improved the patients' ejection fraction of $35 \%$ (the baseline value) by increasing it to $56.5 \%(\mathrm{P}<0.01)$, and LAD was reduced (from 50 to $46 \mathrm{~mm} ; \mathrm{P}<0.01$ ). The present study also demonstrated that cardiac function and the parameters of NT-proBNP and LAD improved in groups 1, 2 and 3, although rosuvastatin therapy was not demonstrated to be associated with an improved cardiac function following CA
Table VI. Multivariate analysis comparing patients with and without $\mathrm{AF}$ recurrence.

\begin{tabular}{llc}
\hline Variable & HR $(95 \% \mathrm{CI})$ & P-value \\
\hline Female & $2.56(0.97-3.58)$ & 0.084 \\
Non-PAF & $0.87(0.41-1.92)$ & 0.155 \\
Duration of AF, months & $1.14(1.09-1.18)$ & 0.011 \\
LVEF, \% & $1.17(0.83-1.90)$ & 0.314 \\
LAD, mm & $1.12(1.06-1.67)$ & 0.049 \\
hs-CRP, mg/l & $1.37(1.11-1.92)$ & 0.002 \\
\hline
\end{tabular}

HR, hazard ratio; CI, confidence interval; hs-CRP, high-sensitivity C-reative protein; PAF, paroxysmal atrial fibrillation; LAD, left atrial diameter; LVEF, left ventricular ejection fraction.

compared with the control group. This may be associated with the type of statin, since a recent meta-analysis of randomized trials illustrated how atorvastatin, and not rosuvastatin, improved cardiac function in HF, and the potential explanation could have been that the uptake of hydrophilic rosuvastatin by the heart is extremely low (27). Another explanation may be that CA itself improved cardiac function significantly, and therefore statins were not responsible for the improvements observed.

Loricchio et al (28) demonstrated that CRP was an independent factor for recurrence of $\mathrm{AF}$ in patients with persistent AF. Similarly to that study, the present study also revealed that hs-CRP is an independent risk factor for recurrence of AF in patients with HF, indicating that inflammation exerted an important role in the germination and maintenance of AF in patients with HF. The basic mechanism to account for this phenomenon would be that infiltration of inflammatory mediators promoted the atrial fibrosis, increasing the risk of AF (29). Increases in the size of the left atrium are conducive to the formation of the matrix, which makes it easier for the occurrence and maintenance of AF (30). With the extension of time of AF, the left atrium gradually expanded. Enlargement of the left atrium causes myocardial cell deformation, leading to changes in the mechanisms of ion-channel electrophysiology, and therefore the excitability and self-regulation of the myocardium may increase (31). These factors would explain why $\mathrm{LAD}$ and the duration of $\mathrm{AF}$ are of value in predicting the recurrence of $\mathrm{AF}$ in patients with $\mathrm{HF}$.

In conclusion, the findings of the present study have demonstrated that treatment with $20 \mathrm{mg}$ rosuvastatin daily following CA may significantly decrease the recurrence rate of AF in patients with HF. The results also demonstrate that LAD, hs-CRP and duration of AF are all independent predictors of AF recurrence in patients with HF. Furthermore, the present study also highlights how CA may improve cardiac function in patients with HF and AF.

\section{Acknowledgements}

We are thankful for the assistance of the participants of this study at the Department of Cardiology of The First Affiliated Hospital of Zhengzhou University. 


\section{References}

1. Lloyd-Jones DM, Larson MG, Leip EP, Beiser A, D'Agostino RB, Kannel WB, Murabito JM, Vasan RS, Benjamin EJ and Levy D; Framingham Heart Study: Lifetime risk for developing congestive heart failure-The Framingham Heart Study. Circulation 106: 3068-3072, 2002.

2. Lloyd-Jones DM, Wang TJ, Leip EP, Larson MG, Levy D, Vasan RS, D'Agostino RB, Massaro JM, Beiser A, Wolf PA and Benjamin EJ: Lifetime risk for development of atrial fibrillation - The Framingham Heart Study. Circulation 110: 1042-1046, 2004.

3. Anselmino M, Matta M and Gaita F: Catheter ablation of atrial fibrillation in patients with heart failure: Can we break the vicious circle? Eur J Heart Fail 17: 1003-1005, 2015.

4. Cooper HA, Bloomfield DA, Bush DE, Katcher MS, Rawlins M, Sacco JD and Chandler M: AFFIRM Investigators: Relation between achieved heart rate and outcomes in patients with atrial fibrillation (from the Atrial Fibrillation Follow-up Investigation of Rhythm Management [AFFIRM] Study). Am J Cardiol 93: 1247-1253, 2004.

5. January CT, Wann LS, Alpert JS, Calkins H, Cigarroa JE, Cleveland JC Jr, Conti JB, Ellinor PT, Ezekowitz MD, Field ME, et al; ACC/AHA Task Force Members: 2014 AHA/ACC/HRS guideline for the management of patients with atrial fibrillation: Executive summary: A report of the American College of Cardiology/American Heart Association Task Force on practice guidelines and the Heart Rhythm Society. Circulation 130: 2071-2104, 2014.

6. Anselmino M, Matta M, D'Ascenzo F, Bunch TJ, Schilling RJ, Hunter RJ, Pappone C, Neumann T, Noelker G, Fiala M, et al: Catheter ablation of atrial fibrillation in patients with left ventricular systolic dysfunction: A systematic review and meta-analysis. Circ Arrhythm Electrophysiol 7: 1011-1018, 2014.

7. Young-Xu Y, Jabbour S, Goldberg R, Blatt CM, Graboys T, Bilchik B and Ravid S: Usefulness of statin drugs in protecting against atrial fibrillation in patients with coronary artery disease. Am J Cardiol 92: 1379-1383, 2003.

8. Horwich TB, MacLellan WR and Fonarow GC: Statin therapy is associated with improved survival in ischemic and non-ischemic heart failure. J Am Coll Cardiol 43: 642-648, 2004.

9. Maggioni AP, Fabbri G, Lucci D, Marchioli R, Franzosi MG, Latini R, Nicolosi GL, Porcu M, Cosmi F, Stefanelli S, et al GISSI-HF Investigators: Effects of rosuvastatin on atrial fibrillation occurrence: Ancillary results of the GISSI-HF trial. Eur Heart J 30: 2327-2336, 2009

10. Xia W, Yin Z, Li J, Song Y and Qu X: Effects of rosuvastatin on asymmetric dimethylarginine levels and early atrial fibrillation recurrence after electrical cardioversion. Pacing Clin Electrophysiol 32: 1562-1566, 2009.

11. Yancy CW, Jessup M, Bozkurt B, Butler J, Casey DE Jr, Drazner MH, Fonarow GC, Geraci SA, Horwich T, Januzzi JL, et al: American College of Cardiology Foundation; American Heart Association Task Force on Practice Guidelines: 2013 ACCF/AHA guideline for the management of heart failure: A report of the American College of Cardiology Foundation/American Heart Association Task Force on Practice Guidelines. J Am Coll Cardiol 62: e147-e239, 2013.

12. Hunt SA, Abraham WT, Chin MH, Feldman AM, Francis GS, Ganiats TG, Jessup M, Konstam MA, Mancini DM, Michl K, et al: American College of Cardiology, American Heart Association Task Force on Practice Guidelines, American College of Chest Physicians, International Society for Heart and Lung Transplantation, Heart Rhythm Society: ACC/AHA 2005 Guideline Update for the Diagnosis and Management of Chronic Heart Failure in the Adult: A report of the American College of Cardiology/American Heart Association Task Force on Practice Guidelines (Writing Committee to Update the 2001 Guidelines for the Evaluation and Management of Heart Failure): Developed in collaboration with the American College of Chest Physicians and the International Society for Heart and Lung Transplantation: Endorsed by the Heart Rhythm Society. Circulation 112: e154-e235, 2005.

13. Ponikowski P, Voors AA, Anker SD, Bueno H, Cleland JG, Coats AJ, et al: ESC Guidelines for the Diagnosis and Treatment of Acute and Chronic Heart Failure. Rev Esp Cardiol: 69 1167, 2016.
14. Imai E, Horio M, Nitta K, Yamagata K, Iseki K, Tsukamoto $Y$, Ito S, Makino H, Hishida A and Matsuo S: Modification of the modification of diet in Renal Disease (MDRD) study equation for Japan. Am J Kidney Dis 50: 927-937, 2007.

15. Hunter RJ, Berriman TJ, Diab I, Kamdar R, Richmond L, Baker V, Goromonzi F, Sawhney V, Duncan E, Page SP, et al: A randomized controlled trial of catheter ablation versus medical treatment of atrial fibrillation in heart failure (the CAMTAF trial). Circ Arrhythm Electrophysiol 7: 31-38, 2014.

16. Thihalolipavan S and Morin DP: Atrial fibrillation and heart failure: Update 2015. Prog Cardiovasc Dis 58: 126-135, 2015.

17. Machino-Ohtsuka T, Seo Y, Ishizu T, Sugano A, Atsumi A, Yamamoto $M$, Kawamura $R$, Machino $T$, Kuroki $K$, Yamasaki H, et al: Efficacy, safety, and outcomes of catheter ablation of atrial fibrillation in patients with heart failure with preserved ejection fraction. J Am Coll Cardiol 62: 1857-1865, 2013.

18. Maron DJ, Fazio S and Linton MF: Current perspectives on statins. Circulation 101: 207-213, 2000.

19. Liao JK and Laufs U: Pleiotropic effects of statins. Annu Rev Pharmacol Toxicol 45: 89-118, 2005.

20. Kim YM, Guzik TJ, Zhang YH, Zhang MH, Kattach H, Ratnatunga C, Pillai R, Channon KM and Casadei B: A myocardial Nox 2 containing $\mathrm{NAD}(\mathrm{P}) \mathrm{H}$ oxidase contributes to oxidative stress in human atrial fibrillation. Circ Res 97: 629-636, 2005.

21. Reilly SN, Jayaram R, Nahar K, Antoniades C, Verheule S, Channon KM, Alp NJ, Schotten U and Casadei B: Atrial sources of reactive oxygen species vary with the duration and substrate of atrial fibrillation: Implications for the antiarrhythmic effect of statins. Circulation 124: 1107-1117, 2011.

22. Recalde A, Carnicer R, Simon J, Reilly S, Verheule S, Shah AM, et al: Increased atrial fibrillation susceptibility in mice with myocardial specific NOX2 overexpression is prevented by short term statin treatment. Eur Heart J 35: 1118, 2014

23. Peña JM, MacFadyen J, Glynn RJ and Ridker PM: High-sensitivity C-reactive protein, statin therapy, and risks of atrial fibrillation: An exploratory analysis of the JUPITER trial. Eur Heart J 33: 531-537, 2012.

24. Walfridsson H, Walfridsson U, Nielsen JC, Johannessen A, Raatikainen P, Janzon M, Levin LA, Aronsson M, Hindricks G, Kongstad O, et al: Radiofrequency ablation as initial therapy in paroxysmal atrial fibrillation: Results on health-related quality of life and symptom burden. The MANTRA-PAF trial. Europace 17: 215-221, 2015.

25. Morillo CA, Verma A, Connolly SJ, Kuck KH, Nair GM, Champagne J, Sterns LD, Beresh H, Healey JS and Natale A: RAAFT-2 investigators: Radiofrequency ablation vs antiarrhythmic drugs as first-line treatment of paroxysmal atrial fibrillation (RAAFT-2): A randomized trial. JAMA 311: 692-700, 2014.

26. Rillig A, Makimoto H, Wegner J, Lin T, Heeger C, Lemes C, Fink T, Metzner A, Wissner E, Mathew S, et al: Six-year clinical outcomes after catheter ablation of atrial fibrillation in patients with impaired left ventricular function. J Cardiovasc Electrophysiol 26: 1169-1179, 2015.

27. Takagi $\mathrm{H}$ and Umemoto $\mathrm{T}$ : Atorvastatin, not rosuvastatin, improves cardiac function in heart failure: A meta-analysis of randomized trials. Int J Cardiol 155: 296-299, 2012.

28. Loricchio ML, Cianfrocca C, Pasceri V, Bianconi L, Auriti A, Calo L, Lamberti F, Castro A, Pandozi C, Palamara A, et al: Relation of C-reactive protein to long-term risk of recurrence of atrial fibrillation after electrical cardioversion. Am J Cardiol 99: 1421-1424, 2007.

29. Schiffrin EL: The immune system: Role in hypertension. Can J Cardiol 29: 543-548, 2013.

30. Xu J, Cui G, Esmailian F, Plunkett M, Marelli D, Ardehali A, Odim J, Laks H and Sen L: Atrial extracellular matrix remodeling and the maintenance of atrial fibrillation. Circulation 109: 363-368, 2004

31. Jalife J and Kaur K: Atrial remodeling, fibrosis, and atrial fibrillation. Trends Cardiovasc Med 25: 475-484, 2015. 